\title{
Effects of pulsatile and nonpulsatile perfusion on cerebral hemodynamics investigated with a new pediatric pump
}

\author{
Akif Ündar, PhD, ${ }^{\mathrm{a}, \mathrm{b}, \mathrm{c}}$ Harald C. Eichstaedt, MD, ${ }^{\mathrm{c}}$ Joyce E. Bigley, $\mathrm{CCP},{ }^{c}$ Blake A. Deady, BS, ${ }^{\mathrm{c}}$ Aimee E. Porter, BS, ${ }^{\mathrm{c}}$ \\ William K. Vaughn, PhD, ${ }^{\mathrm{d}}$ and Charles D. Fraser, Jr, MD, ${ }^{\mathrm{a}, \mathrm{c}, \mathrm{e}}$ Houston, Tex
}

$\mathrm{T}$ o repair complex congenital heart defects, surgeons are required to use extreme techniques, such as cardiopulmonary bypass $(\mathrm{CPB})$ with deep hypothermic circulatory arrest (DHCA). Several investigators have shown that DHCA has a significant adverse effect on the cerebral blood flow $(\mathrm{CBF})$ and metabolism in neonates and infants, as well as in animal models. ${ }^{1-3}$ However, we have shown, in a neonatal piglet model, that the use of pulsatile flow might minimize these adverse events by increasing the regional and global CBF, cerebral metabolic rate of oxygen, and cerebral oxygen delivery and by decreasing cerebral vascular resistance. ${ }^{4}$ In a separate study we have also shown that, compared with nonpulsatile roller pumps, pulsatile roller pumps generate significantly more hemodynamic energy and increase cerebral, renal, and myocardial blood flow after DHCA. ${ }^{5-7}$

The objectives of the present study were (1) to compare the effects of pulsatile perfusion versus nonpulsatile perfusion with a

From the Congenital Heart Surgery Service, Texas Children's Hospital, a the Division of Congenital Heart Surgery, Michael E. DeBakey Department of Surgery, Baylor College of Medicine, ${ }^{\mathrm{b}}$ the Cullen Cardiovascular Surgical Research Laboratories, Texas Heart Institute, ${ }^{c}$ the Department of Biostatistics and Epidemiology, Texas Heart Institute, ${ }^{\mathrm{d}}$ and the Department of Pediatrics, Baylor College of Medicine, ${ }^{\mathrm{e}}$ Houston, Tex.

This study was supported by a grant from the American Heart Association, Texas Affiliate, to Dr Akif Ündar (grant 98BG197).

Received for publication Feb 7, 2002; accepted for publication March 29, 2002.

Address for reprints: Akif Ündar, PhD, Texas Children's Hospital/Baylor College of Medicine, Congenital Heart Surgery Service, 6621 Fannin St, Mail Code WT 19345-H, Houston, TX 77030-2399 (E-mail: aundar@bcm.tmc.edu).

J Thorac Cardiovasc Surg 2002;124:413-6

Copyright $(92002$ by The American Association for Thoracic Surgery

$0022-5223 / 2002 \$ 35.00+0 \quad \mathbf{1 2 / 5 4 / 1 2 5 2 0 9}$

doi:10.1067/mtc.2002.125209 new pediatric roller pump equipped with a miniature roller head on regional and global $\mathrm{CBF}$ and on regional cerebral oxygen saturation $\left(\mathrm{rSo}_{2}\right)$ and (2) to quantify and directly compare the resulting pressure and flow waveforms in terms of hemodynamic energy by using the energy equivalent pressure (EEP) formula. The EEP formula is the best for quantifying different modes of perfusion because it contains both pressure and flow waveforms and not just pressure waveforms alone. ${ }^{8}$

\section{Materials and Methods}

Animals. Fourteen piglets (mean weight, $3 \mathrm{~kg}$ ) underwent either pulsatile perfusion $(n=7)$ or nonpulsatile perfusion $(n=7)$. All animals received humane care as described in the "Guide for the Care and Use of Laboratory Animals" of the National Research Council.

Perfusion protocol. Each piglet was premedicated with intramuscular ketamine hydrochloride $(20 \mathrm{mg} / \mathrm{kg}$ ) and acepromazine maleate ( $1 \mathrm{mg} / \mathrm{kg}$; INN: acepromazine). An intravenous line was established, after which a 3-mm endotracheal tube was inserted for mechanical ventilation. Intravenous boluses of fentanyl citrate $(100 \mu \mathrm{g} / \mathrm{kg})$ and pancuronium bromide $(0.3 \mathrm{mg} / \mathrm{kg})$ were then given. During $\mathrm{CPB}$, anesthesia was maintained with continuous isoflurane $(1 \%-5 \%)$ by means of oxygenator gas inflow. A median sternotomy was performed, after which the ascending aorta and right atrium were cannulated with a $10 \mathrm{~F}$ aortic cannula (DLP, Inc, Grand Rapids, Mich) and a $21 \mathrm{~F}$ single-stage venous cannula (Polystan A/S, Varlose, Denmark), respectively. The extracorporeal circuit was primed with heparinized fresh blood and lactated Ringer's solution. The priming volume for the whole circuit was approximately $600 \mathrm{~mL}$. During CPB, the hematocrit level was maintained at $24 \%$ to $26 \%$ in both groups. Equipment used in the circuit included a Stöckert SIII mast-mounted roller pump with a miniature roller head (Stöckert, Munich, Germany) for producing pulsatile and nonpulsatile flow, a hollow-fiber membrane oxygenator (Capiox SX10; Terumo Corp, Tokyo, Japan), and a pediatric 


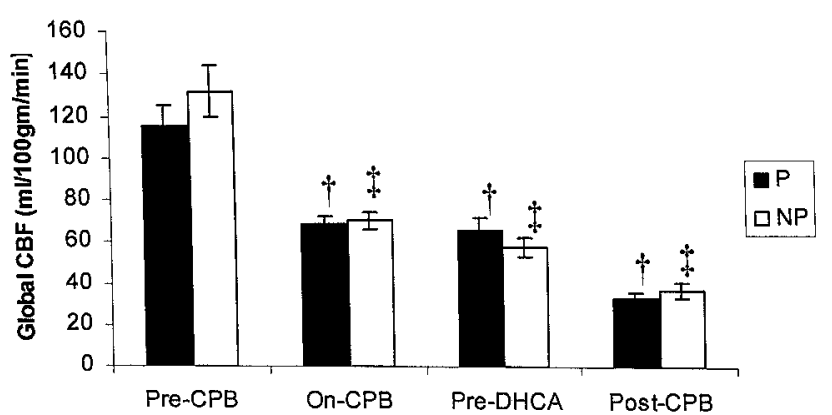

Figure 1. Global CBF (mean $\pm S E M) .+P<.05$ versus pre-CPB flow within pulsatile perfusion group; $¥ P<.05$ versus pre-CPB flow within nonpulsatile perfusion group. $P$, Pulsatile; NP, nonpulsatile.

arterial filter (Terumo Corp). During pulsatile CPB, the pump rate was maintained at 150 beats/min. Pump flow was maintained at $150 \mathrm{~mL} \cdot \mathrm{kg}^{-1} \cdot \mathrm{min}^{-1}$ in both groups. An ultrasonic flow probe (T109; Transonic Systems, Inc, Ithaca, NY) was placed in the circuit, beyond the membrane oxygenator, to measure blood flow. In all experiments phenoxybenzamine $(1 \mathrm{mg} / \mathrm{kg})$, a potent vasodilator and $\alpha$-adrenergic blocker, was administered 5 minutes before initiation of $\mathrm{CPB}$. During $\mathrm{CPB}$, the mean arterial pressure (MAP) was maintained at $45 \mathrm{~mm} \mathrm{Hg}$ by adding isoflurane through the oxygenator gas inflow conduit in both groups. During the 60minute aortic crossclamping period, the temperature was kept at $18^{\circ} \mathrm{C}$ in both groups. After the ascending aorta was crossclamped, a 40-mL dose of crystalloid cardioplegic (modified Kirklin) solution was manually administered into the aorta. At the end of each experiment, the piglet was killed with an intravenous bolus of pentobarbital sodium and phenytoin sodium (Beuthanasia-D, 0.22 $\mathrm{mg} / \mathrm{kg})$.

Experimental design. Both experimental groups underwent hypothermia for 25 minutes, DHCA for 60 minutes, cold reperfusion for 10 minutes, and rewarming for 40 minutes. During cooling and rewarming, alpha-stat management was used. Rectal temperature was measured continuously in both groups.

Radioactive microspheres, $15 \mu \mathrm{m}$ in diameter $\left({ }^{51} \mathrm{Cr},{ }^{95} \mathrm{Nb}\right.$, ${ }^{141} \mathrm{Ce},{ }^{46} \mathrm{Sc}$ ), were used to measure regional and global CBF. In both experimental perfusion groups, microspheres were injected (1) before $\mathrm{CPB}$, (2) during normothermic $\mathrm{CPB}$ at $36^{\circ} \mathrm{C}$, (3) during deep hypothermia at $18^{\circ} \mathrm{C}$, and (4) 30 minutes after CPB. Microspheres were injected into the site of the arterial line $40 \mathrm{~cm}$ proximal to the aortic cannula during $\mathrm{CPB}$ and into the left atrial catheter before and after CPB. A reference blood sample was withdrawn from the femoral artery before each injection at a pump flow rate of $2 \mathrm{~mL} / \mathrm{min}$. At the end of each experiment, the brain was removed and dissected. The left and right cerebral hemispheres, cerebellum, basal ganglia, and brain stem were then placed in preweighted tubes for gamma counting. The radiolabeled microsphere technique is detailed elsewhere. ${ }^{4,6}$

$\mathbf{r S O}_{2}$ measurements. For continuous monitoring of the $\mathrm{rSO}_{2}$ of the mixed arterial and venous blood in the brain cortex, a pediatric near-infrared (NIR) spectroscope (INVOS Model 5100; Somanetics Corp, Troy, Mich) was used. This device passed low-intensity NIR light into the subject's forehead through the

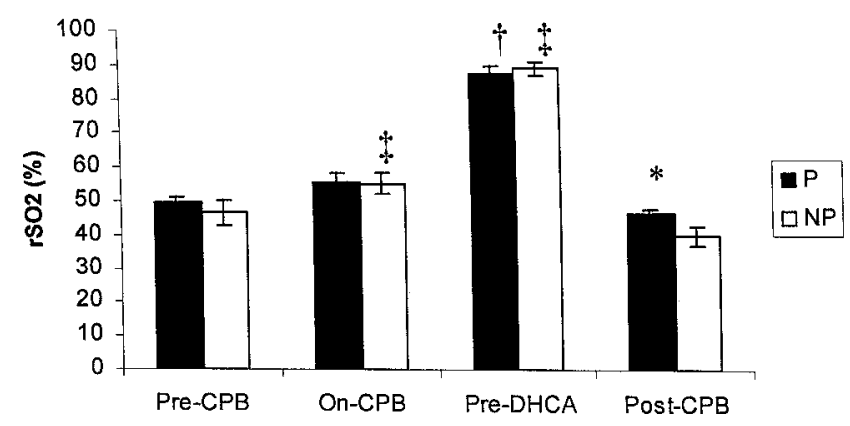

Figure 2. Regional cerebral oxygen saturation (mean $\pm S E M$ ). ${ }^{*} \boldsymbol{P}<.05$ pulsatile versus nonpulsatile perfusion groups; $+\boldsymbol{P}<.05$ versus pre-CPB flow within pulsatile perfusion group; $¥ P<.05$ versus pre-CPB flow within nonpulsatile perfusion group. $P$, Pulsatile; $N P$, nonpulsatile.

skull and the cerebral cortex. The degree of spectral absorption by the cerebral circulation was indicated by the intensity of the reflected light 3 and $4 \mathrm{~cm}$ from the light source. Light absorption data were collected 15 times per second and were stored on a diskette for computer analysis.

Quantification of pulsatile and nonpulsatile pressure-flow waveforms. The following formula is used to define EEP (8):

$$
\mathrm{EEP}=\left(\int \mathrm{pdt}\right) /\left(\int \mathrm{dt}\right),
$$

where $\mathrm{f}$ is the pump flow rate (in milliliters per second), $\mathrm{p}$ is the arterial pressure, and the time integrals are over one pulse cycle. The EEP is the ratio of the areas beneath the hemodynamic power curve $\left(\int \mathrm{pdt}\right)$ and pump flow rate curve $\left(\int \mathrm{dt}\right)$ at the end of the flow and pressure cycles. The EEP is expressed in millimeters of mercury.

Waveforms of the femoral MAP, precannulation extracorporeal circuit pressure, and pump flow were acquired at 3 experimental stages: (1) during normothermic CPB (15 minutes on pump at $36^{\circ} \mathrm{C}$ ); (2) during deep hypothermic $\mathrm{CPB}$ (immediately before DHCA at $18^{\circ} \mathrm{C}$ ); and (3) after rewarming (after 60 minutes of DHCA, 10 minutes of cold reperfusion, and 40 minutes of rewarming). Data were recorded by using data acquisition software for 15 seconds at a rate of $100 \mathrm{~Hz}$.

Statistical analysis. Two-sided analysis of variance with repeated measures was used for statistical analysis of data from the pulsatile and nonpulsatile perfusion groups. All regional and global CBF results were expressed as means \pm SEM.

\section{Results}

There were no intergroup differences in hematocrit level, temperature, arterial oxygen tension, and arterial carbon dioxide tension at any of the 4 experimental stages.

Global $\boldsymbol{C B F}$. In both groups global CBF diminished during normothermic CPB compared with before CPB (115.4 \pm 9.7 $\mathrm{mL} / 100 \mathrm{~g}$ per minute vs $68 \pm 4.1 \mathrm{~mL} / 100 \mathrm{~g}$ per minute, $P<0.05$ in the pulsatile perfusion group; $131.3 \pm 12.1 \mathrm{~mL} / 100 \mathrm{~g}$ per minute vs $69.8 \pm 4 \mathrm{~mL} / 100 \mathrm{~g}$ per minute, $P<.05$ in the nonpulsatile perfusion group; Figure 1). During deep hypothermic $\mathrm{CPB}$ or 30 minutes after $\mathrm{CPB}$, there were no intergroup differences in global $\mathrm{CBF}$. 
TABLE 1. Regional cerebral blood flow*

\begin{tabular}{|c|c|c|c|c|c|c|c|c|}
\hline \multirow[b]{2}{*}{ Region } & \multicolumn{2}{|c|}{ Pre-CPB } & \multicolumn{2}{|c|}{ On CPB } & \multicolumn{2}{|c|}{ Pre-DHCA } & \multicolumn{2}{|c|}{ Post-CPB } \\
\hline & $\mathbf{P}$ & NP & $\mathbf{P}$ & NP & $\mathbf{P}$ & NP & $\mathbf{P}$ & NP \\
\hline Left cerebral hemisphere & $100.2 \pm 8.7$ & $118.7 \pm 11.5$ & $56.2 \pm 3.3 \dagger$ & $61.4 \pm 4.5 \dagger$ & $54.6 \pm 5.6 \dagger$ & $49.2 \pm 3.8 \ddagger$ & $27.5 \pm 1.4 \dagger$ & $31.3 \pm 3.2 \ddagger$ \\
\hline Right cerebral hemisphere & $102.6 \pm 16.6$ & $117.3 \pm 11.3$ & $58.2 \pm 3 \dagger$ & $59.7 \pm 4.6 \ddagger$ & $55.9 \pm 5.3 \dagger$ & $47.6 \pm 3.4 \ddagger$ & $28.4 \pm 1.5 \dagger$ & $31 \pm 3.3 \ddagger$ \\
\hline Basal ganglia and thalamus & $134 \pm 13.5$ & $144.1 \pm 14.2$ & $84.2 \pm 8.6 \dagger$ & $77.4 \pm 6.7 \ddagger$ & $80.7 \pm 10.7 \dagger$ & $69.7 \pm 6.2 \ddagger$ & $37.7 \pm 2.9 \dagger$ & $37.7 \pm 4.1 \ddagger$ \\
\hline Brain stem & $167.7 \pm 14.7$ & $166.5 \pm 14.6$ & $116.9 \pm 9.9 \dagger$ & $102.8 \pm 8.2 \ddagger$ & $111 \pm 11.8 \dagger$ & $93.1 \pm 7.2 \ddagger$ & $41.1 \pm 4.7 \dagger$ & $40.4 \pm 4 \ddagger$ \\
\hline Cerebellum & $165.6 \pm 12.9$ & $187 \pm 17.2$ & $101.1 \pm 5.6 \dagger$ & $110.5 \pm 12.2 \ddagger$ & $91.8 \pm 8.7 \dagger$ & $79.6 \pm 6.9 \ddagger$ & $57.1 \pm 5.1 \dagger$ & $63 \pm 5.5 \ddagger$ \\
\hline
\end{tabular}

$P$, Pulsatile; $N P$, nonpulsatile; $C P B$, cardiopulmonary bypass; $D H C A$, deep hypothermic circulatory arrest.

*Mean \pm SEM $\left(\mathrm{mL} \cdot 100 \mathrm{~g}^{-1} \cdot \mathrm{min}^{-1}\right)$.

$\dagger P<.05$ vs pre-CPB within pulsatile group.

$\ddagger P<.05$ vs pre-CPB within nonpulsatile group.

Left and right cerebral hemispheric blood flow. There were no intergroup differences in left cerebral hemispheric blood flow at any of the 4 experimental stages (Table 1). However, blood flow in the left cerebral hemisphere diminished by 30 minutes after CPB in both the pulsatile and nonpulsatile perfusion groups $(27.5 \pm 1.4$ $\mathrm{mL} / 100 \mathrm{~g}$ per minute vs $31.3 \pm 3.2 \mathrm{~mL} / 100 \mathrm{~g}$ per minute, $P=$ .43). The right cerebral hemispheric blood flow resembled the left cerebral hemispheric blood flow (Table 1).

$\mathbf{r S O}$ saturation. There were no intergroup differences in $\mathrm{rSO}_{2}$ before $\mathrm{CPB}(49.3 \% \pm 1.7 \%$ vs $46.4 \% \pm 3.7 \%, P=.83)$, during normothermic CPB $(54.9 \% \pm 3.2 \%$ vs $54.7 \% \pm 3.1 \%, P=.54)$, or during deep hypothermic CPB $(86.3 \% \pm 2.5 \%$ vs $88 \% \pm 1.9 \%$, $P=.42$; Figure 2). However, $\mathrm{rSo}_{2}$ was significantly higher in the pulsatile perfusion group than in the nonpulsatile perfusion group after CPB $(45.3 \% \pm 1.6 \%$ vs $38.8 \% \pm 2.6 \%, P<.05)$.

EEP (from MAP to EEP). There were no intergroup differences in EEP in the femoral artery during normothermic CPB $(-0.3 \pm 1.6 \mathrm{~mm} \mathrm{Hg}$ vs $-0.2 \pm 1.8 \mathrm{~mm} \mathrm{Hg}, P=.94)$, during deep hypothermic CPB $(-0.2 \pm 1.4 \mathrm{~mm} \mathrm{Hg}$ vs $-0.4 \pm 0.7 \mathrm{~mm} \mathrm{Hg}, P$ $=.83)$, or after rewarming $(-1.8 \pm 1.7 \mathrm{~mm} \mathrm{Hg}$ vs $-0.9 \pm 2.2 \mathrm{~mm}$ $\mathrm{Hg}, P=.54)$.

EEP (from extracorporeal circuit pressure to EEP). There were no intergroup differences in EEP in the precannulation extracorporeal circuit during normothermic CPB $(1.2 \pm 3 \mathrm{~mm} \mathrm{Hg}$ vs $1.3 \pm 1.8 \mathrm{~mm} \mathrm{Hg}, P=.64)$, during deep hypothermic CPB (2.6 \pm $2.2 \mathrm{~mm} \mathrm{Hg}$ vs $1 \pm 0.2 \mathrm{~mm} \mathrm{Hg}, P=.44$ ), or after rewarming $(-0.5 \pm 1.4 \mathrm{~mm} \mathrm{Hg}$ vs $-0.7 \pm 1.3 \mathrm{~mm} \mathrm{Hg}, P=.71)$.

MAP and pulse pressure. There were no differences in MAP between the groups before CPB $(44.3 \pm 2 \mathrm{~mm} \mathrm{Hg}$ vs $48 \pm 3.7 \mathrm{~mm}$ $\mathrm{Hg}, P=.38)$, during normothermic CPB $(44.3 \pm 3.2 \mathrm{~mm} \mathrm{Hg}$ vs $42.8 \pm 1.5 \mathrm{~mm} \mathrm{Hg}, P=.72)$, before DHCA $(44.4 \pm 2.4 \mathrm{~mm} \mathrm{Hg}$ vs $44.6 \pm 1.2 \mathrm{~mm} \mathrm{Hg}, P=.95)$, after rewarming $(46.4 \pm 2.8 \mathrm{~mm}$ $\mathrm{Hg}$ vs $46.4 \pm 4.5 \mathrm{~mm} \mathrm{Hg}, P=.98)$, or after CPB $(50.8 \pm 6 \mathrm{~mm}$ $\mathrm{Hg}$ vs $46.8 \pm 4.6 \mathrm{~mm} \mathrm{Hg}, P=.35)$.

There were no intergroup differences in pulse pressure before CPB $(22.3 \pm 2.2 \mathrm{~mm} \mathrm{Hg}$ vs $22 \pm 3.5 \mathrm{~mm} \mathrm{Hg}, P=.90)$, during $\mathrm{CPB}(8.6 \pm 2.8 \mathrm{~mm} \mathrm{Hg}$ vs $5 \pm 0.4 \mathrm{~mm} \mathrm{Hg}, P=.14)$, before DHCA $(5.3 \pm 0.5 \mathrm{~mm} \mathrm{Hg}$ vs $4.6 \pm 0.7 \mathrm{~mm} \mathrm{Hg}, P=.76)$, after rewarming $(7.6 \pm 1.3 \mathrm{~mm} \mathrm{Hg}$ vs $5.3 \pm 1.3 \mathrm{~mm} \mathrm{Hg}, P=.34)$, or after CPB $(22.7 \pm 1.8 \mathrm{~mm} \mathrm{Hg}$ vs $22.4 \pm 1.1 \mathrm{~mm} \mathrm{Hg}, P=.90)$.

\section{Discussion}

In our previous experiments we documented that pulsatile pumps (hydraulically driven or roller) generate significantly more hemo- dynamic energy than do conventional nonpulsatile roller pumps. ${ }^{5,7}$ This extra energy produced by pulsatile pumps might maintain better microcirculation. ${ }^{5-7}$ In the present study we found no differences in hemodynamic energy levels produced by pulsatile versus nonpulsatile pumps. In fact, the particular pediatric pulsatile roller pump used in this study, which had a miniature roller head, failed to produce more energy. This might be why there were no differences in regional and global CBF and cerebral oxygenation between groups. The pulse pressures between groups were also similar during CPB. When the temperature was reduced from $36^{\circ} \mathrm{C}$ to $18^{\circ} \mathrm{C}, \mathrm{rSO}_{2}$ significantly increased in both groups as a result of the increase in metabolic oxygen suppression. There were no intergroup differences in $\mathrm{rSO}_{2}$ levels during CPB. Deep hypothermic CPB with DHCA severely impaired cerebral hemodynamics in both groups after CPB.

For many years, our laboratory has been interested in the effects of pulsatile perfusion on cerebral, renal, and myocardial recovery after hypothermic CPB with or without the use of DHCA in a pediatric model. ${ }^{3-7}$ We have also tested all Food and Drug Administration-approved pediatric pulsatile roller pumps currently available in the United States, as well as other experimental pumps (not Food and Drug Administration approved), in the identical experimental setting used in this current study. ${ }^{5}$ In all our previous experiments, we have clearly documented that cerebral, renal, and myocardial recovery after DHCA is significantly better when the pulsatile flow is used.4,6,7 In addition, in those earlier experiments we have also shown that the hemodynamic energy produced by all other pulsatile pumps, except the one used in the current study, generated higher hemodynamic energy compared with the nonpulsatile roller pumps. ${ }^{5}$ The results of this study clearly show that not all pulsatile pumps are truly pulsatile. We believe that each study that investigates the effects of perfusion modes on vital organ blood flow should also include the hemodynamic energy generated by each of the pulsatile and nonpulsatile devices. The readers of any article on perfusion modes should know whether there is a difference in hemodynamic energy, along with other physiologic parameters. Therefore we urge other investigators to use the EEP formula for a precise quantification of pressure and pump flow waveforms between different modes of perfusion or different forms of pulsatility for a direct and meaningful comparison. ${ }^{5}$

Despite the negative results on this particular study, we truly believe that pulsatile perfusion is superior to the nonpulsatile flow on cerebral, renal, and myocardial recovery, when the adequate 
pulsatility is achieved. ${ }^{3-7}$ We also believe that our current results correlated well with our earlier publications.

In summary, our present data indicate that a pediatric pulsatile roller pump equipped with a miniature roller head is no better than a nonpulsatile pump equipped with a miniature roller head at generating adequate hemodynamic energy or maintaining cerebral hemodynamics during $\mathrm{CPB}$ with DHCA. The data also suggest that (1) NIR spectroscopy, both real time and noninvasive, is a useful technique for monitoring $\mathrm{rSO}_{2}$, and (2) the EEP formula should be used to evaluate directly and comparatively the benefits of pulsatile perfusion.

We thank Kathleen McKay, BS, for technical assistance during the experiments.

\section{References}

1. Greeley WJ, Kern FH, Meliones JN, Ungerleider RM. Effect of deep hypothermia and circulatory arrest on cerebral blood flow and metabolism. Ann Thorac Surg. 1993;56:1464-6.
2. Greeley WJ, Kern FH, Mault JR, Skaryak LA, Ungerleider RM. Mechanisms of injury and methods of protection of the brain during cardiac surgery in neonates and infants. Cardiol Young. 1993;3:317-30.

3. Ündar A, Vaughn WK, Calhoon JH. The effects of cardiopulmonary bypass and deep hypothermic circulatory arrest on blood viscoelasticity and cerebral blood flow in a neonatal piglet model. Perfusion. 2000;15:121-8.

4. Ündar A. Design and performance of physiologic pulsatile flow cardiopulmonary bypass systems for neonates and infants [dissertation] Austin, Tex: The University of Texas at Austin; 1996.

5. Ündar A, Eichstaedt HC, Masai T, et al. Comparison of six pediatric cardiopulmonary bypass pumps during pulsatile and nonpulsatile perfusion. J Thorac Cardiovasc Surg. 2001;122:827-9.

6. Ündar A, Masai T, Yang SQ, Goddard-Finegold J, Frazier OH, Fraser CD Jr. Effects of perfusion mode on regional and global organ blood flow in a neonatal piglet model. Ann Thorac Surg. 1999;68:1336-43.

7. Ündar A, Masai T, Yang SQ, et al. Pulsatile perfusion improves regional myocardial blood flow during and after hypothermic cardiopulmonary bypass in a neonatal piglet model. ASAIO J 2002;48:90-95.

8. Shepard RB, Simpson DC, Sharp JF. Energy equivalent pressure. Arch Surg. 1966;93:730-40.

\section{Authoritative}

The Journal of Thoracic and Cardiovascular Surgery is the most frequently cited thoracic/cardiovascular surgery journal in the Science Citation Index. An article in JTCVS is sited on average almost twice as often as those in the closest cardiothoracic journal. 